\title{
KOMPARASI PEMIKIRAN BERWICK SAYERS DAN MARY MORTIMER TENTANG SISTEM KLASIFIKASI PERPUSTAKAAN
}

\author{
Nurul Fadilla ${ }^{1}$ \\ ${ }^{1}$ Pascasarjana UIN Sunan Kalijaga Yogyakarta \\ Korespondensi: Nrlfdila@gmail.com
}

Diajukan: 05-12-2020; Direview: 14-12-2020; Direvisi: 18-12-2020; Diterima: 30-12-2020

\begin{abstract}
This paper focuses on a good library classification system based on the thoughts of Berwick Sayers and Mary Mortimer. It compares and looks at the relevance of these thoughts. This study applied a qualitative approach and comparative descriptive analysis. Both Berwick Sayers and Mary Mortimer have been famous for their works including the library classification system. Based on the results of a comparison between their thoughts, the study found four fundamental differences. The differences cover 1) A good form of classification is easy to use as explicitly proposed by Mary Mortimer because a 'good version'for the librarian is not necessarily a 'good version' for the library user. Thus, the result will be different. However, if it is easy to use for the user, then it is certainly a good classification form. Meanwhile, Berwick Sayers does not provide an assertive statement but only explains about a good classification; 2) Simple notation versus specific notation; 3) Fitted with a geographical table; 4) Alphabetical versus systematical. Further, the study found four similarities between those thoughts, such as 1) Cover all fields of science; 2) Accommodate new scientific subjects and notations; 3) Develop new science, and 4) Have a supervisory board. Explicitly, the idea that can be implemented in the current library is Mary Mortimer's thought, Dewey Decimal Classification.
\end{abstract}

Keywords: Figure, Classification, Library Classification System, Comparison of Figures, Berwick Sayers, Mary Mortimer

\begin{abstract}
ABSTRAK
Tulisan ini membahas bagaimana sistem klasifikasi perpustakaan yang baik dan bersumber dari hasil pemikiran Berwick Sayers dan Mary Mortimer, kemudian dilakukan komparasi serta dilihat kerelevansian atas hasil pemikiran tersebut. Tulisan ini menggunakan pendekatan kualitatif. Analisis dilakukan secara deksriptif komparatif. Berwick Sayers dan Mary Mortimer telah dikenal banyak memunculkan pemikiranpemikiran dan menghasilkan karya-karya salah satunya tentang sistem klasifikasi perpustakaan. Dari hasil komparasi pemikiran yang telah dilakukan tentang sistem klasifikasi perpustakaan, terdapat empat hal perbedaan yang mendasar diantara kedua tokoh tersebut. Perbedaan tersebut terletak pada 1) Bentuk klasifikasi yang baik itu adalah yang mudah digunakan, pernyataan tersebut secara tegas diberikan oleh Mary Mortimer, karena baik versi pustakawan belum tentu baik versi pemustaka, sehingga akan berbeda hasilnya, namun yang mudah digunakan bagi pemustaka, sudah pasti baik bentuk klasifikasinya, sedangkan Berwick Sayers tidak memberikan pernyataan yang menegaskan namun hanya menjelaskan perihal klasifikasi yang baik, 2) Notasi yang sederhana vs notasi yang spesifik, 3) Memiliki tabel geografis, 4) Alfabetis vs
\end{abstract}


sistematis. Dan didapat pula empat persamaan yaitu 1) Meliputi seluruh bidang ilmu pengetahuan, 2) Mampu mengakomodasi subjek dan notasi ilmu pengetahuan yang baru, 3) Melakukan pengembangan pada ilmu pengetahuan baru, dan 4) Mempunyai suatu badan pengawas. Secara eksplisit, pemikiran yang bisa diimplementasikan pada perpustakaan saat ini adalah pemikiran Mary Mortimer yaitu Dewey Decimal Classification.

Kata Kunci: Tokoh, Klasifikasi, Sistem Klasifikasi Perpustakaan, Berwick Sayers, Mary Mortimer

\section{PENDAHULUAN}

Dalam Undang-Undang Nomor 43 Tahun 2007 Pasal 1 Ayat 1 tentang Perpustakaan dinyatakan bahwa Perpustakaan adalah institusi pengelola koleksi karya tulis, karya cetak, dan/ atau karya rekam secara profesional dengan sistem yang baku guna memenuhi kebutuhan pendidikan, penelitian, pelestarian, informasi, dan rekreasi para pemustaka. Dan pada Ayat 2 bahwa Koleksi perpustakaan adalah semua informasi dalam bentuk karya tulis, karya cetak, dan/atau karya rekam dalam berbagai media yang mempunyai nilai pendidikan, yang dihimpun, diolah dan dilayankan. Berdasarkan Undang-Undang tersebut jelas disebutkan bahwa perpustakaan merupakan instusi yang bersifat mengelola, menyediakan, memberikan dan menyebarkan informasi bagi para pemustakanya.

Pada perpustakaan terdapat berbagai macam sumber koleksi dan sumber informasi yang biasanya dikemas terlebih dahulu sebelum digunakan oleh pemustakanya. Dalam proses pengemasannya diperlukan semacam sistem untuk dapat mengelompokkan koleksi-koleksi yang ada tersebut. Sistem pengelompokkan koleksi dibuat dengan tujuan untuk mempermudah pustakawan dan pemustaka untuk melakukan proses pencarian dan penemuan kembali atas koleksi serta informasi yang dibutuhkan di dalam perpustakaan. Sistem pengelompokkan koleksi biasa disebut dengan sistem klasifikasi. Klasifikasi atau Classification adalah suatu proses sistem pengelompokkan koleksi untuk memudahkan proses dan mekanisme penyusunan dan proses temu kembali. Sistem pengelompokkan ini memiliki banyak bentuk dan selalu mengalami perkembangan (Lasa HS: 2009, 160). Menurut Towa P. Hamakonda dan J.N.B Tairas (1983, 1), klasifikasi adalah suatu proses kerja pengelompokan yang bersifat sistematis dari pada sejumlah obyek, gagasan, buku atau benda-benda lainnya ke dalam kelas atau golongan tertentu berdasarkan ciri-ciri yang sama. Di dalam klasifikasi bahan pustaka dipergunakan penggolongan berdasarkan beberapa ciri-ciri tertentu. Secara sederhana, dapat dikatakan bahwa klasifikasimerupakan sebuah proses pengelompokkan koleksi bahan pustaka berdasarkan suatu kumpulan subjek, bentuk, objek, dan lainnya dengan menggunakan sistem yang telah ditentukan sebelumnya dengan tujuan mempermudah proses penelusuran, penemuan dan penempatan kembali koleksi perpustakaan ke jajaran rak (Darwis: 2014, 3).

Sebagai sarana penempatan kembali koleksi perpustakaan di dalam rak, klasifikasi memiliki beberapa tujuan seperti membantu pemustaka dalam mengidentikkan dan menglokalisasikan suatu dokumen berdasarkan nomor kelas dan panggil yang telah ditetapkan, serta mengelompokkan semua koleksi atas dokumen yang memiliki kesamaan jenis menjadi satu. Pada dasarnya, menurut SulistyoBasuki (1991, 395) klasifikasi mengarah pada bentuk susunan secara logis dalam berbagai bidang pengetahuan dan seni dalam melakukan penyusunan buku atau dokumen lainnya sesuai dengan bagan klasifikasi. Selain itu, klasifikasi juga bertujuan untuk memberikan 
kesederhanaan dalam penelusuran informasi atau dikenal dengan istilah sistem temu kembali informasi. Information Retrieval secara signifikan memiliki tujuan untuk melakukan pengumpulan dan pengorganisasian atas informasi dalam satu atau lebih wilayah subjek agar dapat ditemukan oleh pemustaka ketika ingin menelusur dan menemukan suatu informasi (Chowdhury, 1999: 1).

Adapun manfaat dariklasifikasi (Taslimah Yusuf, 1996: 95), yakni: 1) Pustakawan dan pemustaka dapat meneliti koleksi yang telah ada di dalam perpustakaan, 2) Pustakawan dapat mengadakan keseimbangan koleksi agar nantinya koleksi semakin berkembang sehingga bertambah banyak, 3) Mudah membuat bibliografi dari satu subjek dalam buku-buku tertentu, 4) Memudahkan dalam menemukan suatu subjek yang dibutuhkan, 5) Memudahkan pengembalian suatu koleksi yang telah dibaca atau dipinjam ke tempat semula.

Selanjutnya, atas manfaat dari klasifikasi maka peneliti tertarik mengkaji lebih dalam perihal sistem klasifikasi perpustakaan yang dirujuk atas pemikiran tokoh. Berdasarkan penelusuran terhadap penelitian sebelumnya, peneliti tidak menemukan fokus penelitian mengenai perbandingan pemikiran tokoh perihal sistem klasifikasi perpustakaan. Akan tetapi, dari hasil penelusuran peneliti menemukan dua penelitian yang membahas perbandingan atau komparasi sistem klasifikasi yang secara langsung merujuk kepada DDC dan UDC. Adapun penelitian tersebut, yaitu:

Pertama penelitian yang berjudul Komparasi Bagan Sistem Klasifikasi Dewey Decimal Classification (DDC) Dengan Universal Decimal Classification (UDC). Hasil penelitian menunjukkan adanya persamaan dan perbedaan entri notasi DDC edisi 22 dengan UDC edisi tahun 2005 (Muswita W. Rahma, 2008). Penelitian kedua merupakan sebuah makalah yang di dokumentasikan oleh Institut Seni Indonesia Yogyakarta yang berjudul Perbandingan Klasifikasi DDC Dan Klasifikasi UDC (2018). Dari hasil penelitian dikatakan bahwa sistem klasifikasi DDC merupakan sistem klasifikasi paling popular di Indonesia, dimana didalamnya menggunakan sistem desimal dan dalam mengembangkan notasinya menggunakan angka Arab dengan menyediakan bagan yang meliputi seluruh bidang pengetahuan yang dibagi dalam sepuluh kelas utama, sedangkan UDC merupakan perluasan dari DDC.

Berdasarkan manfaat yang telah dijelaskan dari adanya klasifikasi, dapat ditarik suatu kesimpulan yakni dalam menentukan suatu sistem klasifikasi yang tepat merupakan hal yang mutlak sangat penting. Notasi dan nomor kelas akan menjadi suatu titik temu paling signifikan antara pustakawan dalam penyediaan, pemustaka dalam pemerolehan koleksi dan bahan pustaka sebagai koleksi yang akan dipergunakan. Sistem klasifikasi dengan caranya membuat keragaman ilmu pengetahuan dapat diorganisasikan agar dapat mudah dipahami yaitu berdasarkan kategori atau disiplin ilmunya. Biasanya pustakawan mengorganisasikannya dengan menentukan nomor kelas atau notasi menurut isi yang terkandung di dalam koleksi bahan pustaka. Sehingga, dalam menentukan sistem klasifikasi harus didasarkan atas pemikiran matang agar hasil pengklasifikasian dapat dikatakan baik. Di dalam penelitian ini selanjutnya dibahas bagaimana sistem klasifikasi yang dikatakan baik menurut kedua tokoh yaitu Berwick Sayers dan Mary Mortimer agar nantinya koleksi yang sudah di klasifikasi dapat ditemukan dengan mudah dan informasi serta kebermanfaatan koleksi tersebut akan dapat dirasakan dan digunakan bagi pemustakanya. 


\section{KAJIAN TEORI}

\section{SISTEM KLASIFIKASI PERPUSTAKAAN}

Class merupakan bahasa latin dari klasifikasi yang memiliki artian berupa pengelompokkan suatu benda yang memiliki kesamaan dan pemisahan benda yang tidak sama, jika dideskripsikan klasifikasi merupakan suatu cara dalam melakukan pemisahan antar kelompok berupa subyek-subyek tertentu ke dalam kelompoknya dengan struktur yang telah tersusun secara sistematis. Klasifikasi juga dikatakan sebagai suatu bentuk penyatuan buku-buku berdasarkan subjek dan isi koleksi bahan pustaka yang ada. (Pawit M.Yusuf dan Yaya S, 2005)

Sistem klasifikasi perpustakaan telah menjadi unsur yang signifikan penting dalam proses pengolahan bahan pustaka dimana nantinya perpustakaan melalui pustakawan akan melakukan pengelompokkan koleksi bahan perpustakaan agar dapat ditemukan kembali oleh pemustakanya. Pada dasarnya, bila sistem klasifikasi adalah konsep dari sistem temu kemabli maka memang harus mempermudah para pemustakanya.

\section{KARYA DAN KONTRIBUSI TOKOH DI BIDANG ILMU PERPUSTAKAAN}

\section{Berwick Sayers}

William Charles Berwick Sayers adalah seorang guru, sejarawan dan pustakawan, yang lahir di Mitcham, Surrey tepatnya pada tanggal 23 Desember 1881, dan meninggal pada tahun 1960. Awal pekerjaannya dimulai pada tahun 1895 , tepatnya di kota Bournemouth saat kepala daerah disana membuka sebuah perpustakaan umum pertama disana, dan Berwick Sayers bekerja sebagai staf asisten junior. Selanjutnya, ia bekerja menghabiskan waktu selama hidupnya di Croydon Public Library pada tahun 1904, dan diangkat menjadi wakil kepala perpustakaan dibawah Ernest A. Savage dan Stanley Jast, dan kemudian menjabat sebagai kepala perpustakaan di Croydon Public Library. Sebelumnya ia hanyalah seorang pustakawan biasa yang bekerja khususnya di bidang klasifikasi perpustakaan, namun apa yang ia kerjakan dan hasilkan lebih diatas ratarata pustakawan pada umumnya. Ia juga berkontribusi dalam memajukan layanan perpustakaan yang dikhususkan untuk anak-anak. Sementara itu, kesuksesannya juga diiringi pekerjaan lainnya sebagai seorang penulis dan guru. Berwick Sayers memiliki hobby menulis puisi, ia meyakini jiwanya telah terbentuk atas jiwa-jiwa sastra.

Dalam perjalanan karirnya ia sangat optimis dalam memajukan dan memberikan perubahan pada perpustakaan. Tepat pada tahun 1938 Berwick Sayers resmi menjadi pimpinan pada Library Association, setelah itu ia bergabung dan mengembangkan Association of Assistant Librarians (AAL) sampai pada tahun 1922, yang kemudian dikenal sampai saat ini sebagai Library Association. Pada dasaranya Association of Assistant Librarians (AAL) dikembangkan karena merasa bahwa pustakawan tidak mendapat keadilan pada saat itu, sehingga dibentuknya asosiasi itu sebagai salah satu bentuk untuk melakukan sharing sesama pustakawan, seperti yang dikatakan oleh Berwick Sayers bahwa maksud dan tujuan Association of Assistant Librarians (AAL) adalah untuk membentuk jaringan dan mitra dari setiap perpustakaan yang ada, membangun platform karena umumnya pustakawan pada saat itu memiliki banyak keluhan, aspirasi bahkan inspirasi yang tidak bisa dikeluarkan dan disampaikan pada saat itu, dan untuk melakukan pengembangan demi menciptakan kemajuan di perpustakaan. Berwick Sayers juga memiliki ambisi untuk dapat membangun dan meningkatkan anggota asosiasi di seluruh negeri. 
Dalam Journal Librarianship (James G. Olle, 1981), dijelaskan bahwa Berwick Sayers telah berkontribusi secara mendalam dengan memberikan transformasi pada layanan perpustakaan di Inggris, transformasi yang ia berikan terlihat dari keputusannya untuk membuat kriteriakriteria klasifikasi perpustakaan, kode kriteria perpustakaan, skema perpustakaan secara mandiri versinya. Setelah itu ia dipercaya untuk menjadi dosen di bidang klasifikasi dan menerbitkan buku pelajaran bahasa inggris tentang kepustakawanan dan pengantar klasifikasi perpustakaan yang pertama kali di terbitkan oleh Grafton pada tahun 1918 yang membuatnya mencapai popularitasnya pada saat itu. Dan tepat pada tahun 1954, cetakannya sudah mencapai edisi kesembilan (Berwick Sayers, 1981: 71).

Setelah meninggal, karyanya masih diingat dan hampir semua orang yang menjadi pustakawan mengetahui karya Berwick Sayers, beberapa karya lainnya yaitu An Introduction to Library Classification with Reading, Question and Examination, A Manual of Classification for Librarians and Bibliographers, The Card Catalogue-A Parctical Manual for Public And Private Libraries, A Short Course in Practical Classification with Special Reference, The Grammer of Classification, An Introduction to Library Classification, The Children's Library: a Practical Manual for Public, School, and Home Libraries, The Library Committee: its Character and Work, James Duff Brown: Manual of Library Economy, Library Local Collection, Sayers' Manual of Classification for Librarians, A Manual of Children's Libraries, The Revision of the Stock of a Public Library, dan lainnya.

\section{Mary Mortimer}

Mary Mortimer adalah seorang guru, pustakawan yang sudah cukup dikenal dikalangan pustakawan atau pun perpustakaan di dunia. Mary Mortimer lahir pada tahun 1794. Ia sudah mendalami bidang perpustakaan dengan melakukan inovasi-inovasi sehingga ia diangkat dan telah dipercaya untuk memegang jabatan pada fokus Ilmu Perpustakaan sebagai kepala pimpinan Library Studies Program tepatnya pada Canberra Intitute of Technology di Canberra, Australia. Selain itu Mary Mortimer juga merupakan seorang direktur di DocMatrix Pty Limited, ia juga merupakan seorang peneliti, akademis dan penulis yang telah menghasilkan banyak karya tulis ilmiah, berikut beberapa hasil karya-karyanya yang telah banyak dijadikan referensi di berbagai kalangan di dunia yaitu Learn Dewey Decimal Classification Edition 21 and Edition 22, Learn Basic Library Skills, Learn Descriptive Cataloging, Library Speak: A Glossary of Terms in Librarianship and Information Technology, When Your partner Dies (Women's Press Handbook), Catskill: A Multimedia Course on AACR2 and MARC, Learn Kinetica Document Delivery, All About Kinetica We, Kinetica Document Delivery Manual, Certificate II in Library and Information Service, The Image of Women and Girls In Children's Book dan lainnya.

\section{PEMIKIRAN BERWICK SAYERS DAN MARY MORTIMER TENTANG SISTEM KLASIFIKASI YANG BAIK}

Berikut beberapa pemikiran Berwick Sayers dan Mary Mortimer tentang sistem klasifikasi perpustakaan dapat dikatakan baik jika mencakupi beberapa komponen-komponen syarat, yaitu sebagai berikut : 
Pemikiran Berwick Sayers tentang Sistem Klasifikasi Perpustakaan

1. Sistem klasifikasi bersifat Universal

Bersifat universal memiliki artian yaitu meliputi seluruh bidang ilmu pengetahuan, sehingga berbagai kalangan dari disiplin keilmuan yang berbeda dapat menggunakan dan memanfaatkan sistem klasifikasi tersebut.

2. Sistem klasifikasi bersifat Terperinci

Bersifat terperinci memiliki artian yaitu benar-benar terperinci dalam membagi bidang-bidang ilmu pengetahuan, sehingga setiap subjek dapat memperoleh tempat yang sama di dalam sistem klasifikasi tersebut dan artinya setiap bahan pustaka akan memperoleh tempat dan bagian yang sama.

3. Sistem klasifikasi bersifat Sistematis

Bersifat sistematis memiliki artian yaitu dengan menggunakan sistem tertentu agar memudahkan bagi penggunanya. Dalam membagi suatu bidang kedalam sub-sub bidang seperti suatu sub bidang merupakan bagian dari sub organisasi dari bidang tersebut. Sehingga, dalam menyiapkan bagan susunannya harus jelas, seperti dari notasi yang bernomor paling kecil diakhiri dengan notasi nomor yang paling besar secara berurutan.

4. Bersifat Fleksibel

Bersifat fleksibel dikarenakan bidang ilmu pengetahuan selalu berkembang sesuai dengan perkembangan zaman sehingga dalam perkembangannya akan terjadi penemuan subjek-subjek baru yang mana hal itu dapat ditampung dalam bagan tanpa merusak atau merubah struktur bagan yang telah ada.

5. Memiliki Notasi yang sederhana

Notasi merupakan suatu simbol yang mewakili suatu subjek, dan di dalam bagan klasifikasi, setiap subjek mempunyai simbol-simbol tertentu. Bagan klasifikasi yang baik umumnya menggunakan notasi yang sederhana dan mudah diingat.

6. Memiliki Indeks

Indeks merupakan suatu daftar kata atau istilah yang disusun secara sistematis, biasanya masing-masing diantaranya mengacu pada suatu tempat. Di dalam indeks bagan klasifikasi yang diacu atau dipedomani adalah notasi.

7. Memiliki Badan Pengawas

Suatu sistem klasifikasi yang baik memiliki suatu badan yang mengawasi perkembangan bagan klasifikasi sesuai dengan perkembangan ilmu pengetahuan yang terjadi, sehingga bagan klasifikasi selalu up-to-date, mutakhir dan tidak ketinggalan zaman (WorldCat, 2019).

\section{Pemikiran Mary Mortimer tentang Sistem Klasifikasi Perpustakaan}

1. Harus lengkap, dan mudah digunakan serta dimanfaatkan sesuai dengan tujuan utama dari sistem klasifikasi.

Pernyataan ini dideskripsikan secara tersirat namun secara tegas dalam pemaknaannya, karena jika di dalami maksudnya, klasifikasi yang baik versi pustakawan belum tentu baik versi pemustaka, sehingga akan berbeda hasilnya, namun yang mudah digunakan bagi pemustaka, sudah pasti baik bentuk klasifikasinya.

2. Harus meliputi seluruh bidang ilmu pengetahuan.

Merujuk pada banyaknya ilmu pengetahuan sehingga klasifikasi harus menyajikan dan mencakup seluruh bidang ilmu pengetahuan selengkap-lengkapnya.

3. Notasinya harus spesifik.

Notasi umumnya adalah serangkaian simbol berupa angka yang mewakili dan mendeskripsikan serangkaian istilah, istilah tersebut harus jelas, efektif dan mudah dalam pemahamannya. Jika diperlukan boleh menyertakan definisi dan pengertian, 
baik cakupan judul ataupun catatan untuk memandu proses pengklasifikasian.

4. Harus memiliki tabel pembagian geografis dan indeks yang alfabetis.

Pembagiannya dilakukan secara merata, dengan kepentingan dan bagianbagian yang sama rata antara satu dengan yang lainnya.

5. Harus senantiasa mampu mengakomodasi notasi baru, jika ditemukannya suatu ilmu pengetahuan yang baru.

Tentunya notasi baru tersebut harus efektif dalam pengakomodasiannya, ini berhubungan dengan perkembangan zaman yang mana pengetahuan terus berkembang dan menghasilkan pengetahuan baru tentunya dengan notasi baru yang akan terus bermunculan.

Harus mempunyai suatu badan pengawas yang ahli pada bidang sistem klasifikKarena perkembangan ilmu yang terjadi akan menghasilkan notasi baru nantinya, maka harus memiliki suatu badan pengawas untuk dapat menangani dan mengamati serta dapat di konsultasikan terlebih dahulu agar notasi baru tersebut dapat dipahami bagi penggunanya nanti.

6. Harus selalu dan senantiasa dilakukan pengembangan.

Pengembangan yang dimaksudkan yaitu dengan cara melakukan revisi agar dapat mengikuti perkembangan dan kehadiran ilmu pengetahuan baru, interpretasi baru, pemahaman serta penilaian-penilaian baru dalam keberlangsungan proses pengembangan keilmuan yang ada (Mary Mortimer, 2007: 9).

\section{METODE PENELITIAN}

Pada dasarnya studi tokoh adalah studi atas kajian secara sistematis, kritis perihal sejarah dari tokoh, baik berasal atas ide atau gagasannya secara orisinal, serta konteks sosio-historis yang mencakupi sang tokoh yang dikaji (Abdul Mustaqim, 2014). Dalam tulisan ini menggunakan metode kualitatif, metode kualitatif yaitu mendeskripsikan serta menjelaskan permasalahan yang akan dibahas, dengan konsep pemikiran yang bersumber dari tokoh dan bermaksud untuk memahami konteks, dan bukan hanya sekedar menggambarkannya. Penelitian kualitatif digunakan dengan tujuan untuk mendapatkan informasi yang sedalam-dalamnya tentang buah pikiran antar tokoh perihal sistem klasifikasi yang baik di perpustakaan. Sumber data yang digunakan terdiri dari data primer dan data sekunder. Dimana data primer berasal dari karya tokoh yaitu Berwick Sayers dalam bukunya An Introduction to Library Classification dan Mary Mortimer yaitu Learn Dewey Decimal Classification. Teknik pengumpulan data yang digunakan adalah dokumentasi. Teknik ini digunakan untuk mengumpulkan data yang berkaitan berdasarkan sumber yang valid. Data berupa dokumen yang dapat dipertanggungjawabkan. Dalam teknik pengumpulan data, selanjutnya triangulasi diartikan sebagai teknik yang bersifat menggabungkan dari sumber data yang telah ada dengan memanfaatkan sumber data lainnya untuk keperluan pengecekan atau sebagai pembanding terhadap suatu data. Triangulasi tersebutlah yang digunakan untuk menguji keabsahan data. Dan pada tahap akhir, dilakukan analisis data secara deskriptif komparatif dengan cara menyusun dan mengelompokkan data (Sukardi, 2014) sehingga memberikan gambaran secara nyata terhadap perbandingan sistem klasifikasi tokoh.

\section{PEMBAHASAN}

Pada dasarnya kedua pemikiran tentang sistem klasifikasi yang baik di perpustakaan di atas memiliki beberapa fokus yang signifikan berbeda yaitu pada perbedaan pertama menurut Mary Mortimer pada point pertama, 
"Klasifikasi harus mudah digunakan serta dimanfaatkan sesuai dengan tujuan utama dari sistem klasifikasi”, sehingga dapat diartikan bahwa klasifikasi yang baik belum tentu mudah digunakan serta dimanfaatkan padahal tujuan utama dari sistem klasifikasi adalah memudahkan proses temu kembali, sementara Berwick Sayers tidak menjelaskan dan menyebutkan perihal hal tersebut, ia hanya menyebutkan beberapa klasifikasi yang baik, namun baik belum tentu mudah digunakan. Inilah point pertama yang paling signifikan berbeda dan terlihat jelas pada pemikiran keduanya.

Perbedaan kedua terletak pada point kelima menurut Berwick Sayers, "Memiliki notasi yang sederhana", yang mana memiliki artian sederhana digambarkan pada simbol yang singkat, sedikit dan tidak terlalu banyak. Sedangkan menurut Mary Mortimer pada point ketiga, "Notasinya harus spesifik", yang mana memiliki arti harus jelas, jelas sendiri dapat digambarkan secara detail dan banyak dengan memberikan simbol-simbol lainnya yang mungkin tidak sederhana.

Perbedaan ketiga terletak pada point keempat menurut Mary Mortimer "Harus memiliki tabel pembagian geografis", dimana tabel pembagian geografis mutlak diperlukan berdasarkan faktor-faktor untuk mempermudahnya dan secara gamblang dan jelas dikatakan pembagian geografis yang diartikan sebagai letak wilayah dan daerah, sedangkan menurut Berwick Sayer "Indeks merupakan suatu daftar kata atau istilah yang disusun secara sistematis, biasanya masingmasing diantaranya mengacu pada suatu tempat", pada dasarnya indeks memanglah mengacu pada suatu tempat, namun Berwick Sayer tidak secara detail menjelaskan tempat apa yang dimaksudkan olehnya, apakah suatu wilayah atau bukan atau bahkan hal lainnya.

Perbedaan keempat terletak pada point yang sama pada perbedaan ketiga diatas, namun dengan pembahasan perbedaan yang berbeda, yaitu menurut Mary Mortimer "Harus memiliki tabel pembagian geografis dan indeks yang alfabetis", dimana indeks alfabetis ini memperjelas proses penyusunannya yang diurut berdasarkan alfabet atau abjad, berbeda dengan Berwick Sayers yang mengatakan bahwa "Indeks merupakan suatu daftar kata atau istilah yang disusun secara sistematis", sistematis yang dimaksud yaitu prosesnya dimulai dari nomor paling kecil dan diakhiri dengan notasi nomor yang paling besar secara berurutan. Menurut Kamus Besar Bahasa Indonesia (KBBI) (2019), sistematis adalah teratur menurut dan menggunakan sistem, sehingga penyusunannya telah tersistem berdasarkan urutan nomor yang paling kecil hingga urutan nomor yang paling besar dan jelas berbeda dengan pernyataan Mary Mortimer. Sebagai contoh, jika ingin merujuk pada indeks DDC, yang mana terdiri dari sejumlah tajuk dengan perincian aspekaspeknya, yang disusun secara alfabetis. Secara singkat, dikatakan bahwa yang bersifat sistematis adalah bagan, dan indeks secara alfabetis (Towa P. Hamakonda dan J.N.B. Tairas, 1983: 12). Bagan merupakan skema klasifikasi yang menjabarkan subordinasi dari suatu kelas untuk menunjukkan adanya hubungan hierarkhi, sedangkan indeks subjek adalah rincian istilah tentang berbagai macam pengertian yang diuraikan dalam suatu pustaka yang disusun secara alfabetis (Lasa, 2009: 34).

Selanjutnya, kerelevansian berupa persamaan antara kedua pemikiran tentang sistem klasifikasi yang baik, yaitu pertama, harus meliputi seluruh bidang ilmu pengetahuan, yang kedua, harus selalu dan senantiasa mampu mengakomodasi subjek dan notasi baru karena perkembangan zaman selalu menghasilkan suatu ilmu pengetahuan yang baru, yang ketiga, harus selalu dan senantiasa melakukan pengembangan terutama pada ilmu pengetahuan baru, dan yang keempat 
harus mempunyai suatu badan pengawas yang mempunyai keahlian pada sistem klasifikasi dan bertugas untuk memantau dan mengawasi perkembangan klasisfikasi.
Berikut akan diberikan tabel atas perbedaan dan persamaan tentang sistem klasifikasi yang baik hasil dari pemikiran kedua tokoh, yaitu sebagai berikut:

Tabel 1. Komparasi Pemikiran Kedua Tokoh

\begin{tabular}{|c|c|c|c|}
\hline $\begin{array}{l}\text { NAMA } \\
\text { TOKOH }\end{array}$ & TEORI PEMIKIRAN & PERBEDAAN & PERSAMAAN \\
\hline $\begin{array}{l}\text { Berwick } \\
\text { Sayers }\end{array}$ & $\begin{array}{l}\text { a. Sistem klasifikasi bersifat } \\
\text { Universal. } \\
\text { b. Sistem klasifikasi bersifat } \\
\text { Terperinci. } \\
\text { c. Sistem klasifikasi bersifat } \\
\text { Sistematis. } \\
\text { d. Bersifat Fleksibel. } \\
\text { e. Memiliki Notasi yang sederhana. } \\
\text { f. Memiliki Indeks. } \\
\text { g. Memiliki Badan Pengawas. }\end{array}$ & $\begin{array}{l}\text { a. Notasi } \\
\text { sederhana. } \\
\text { b. Indeks secara } \\
\text { sistematis. } \\
\text { c. Tidak } \\
\text { menjelaskan } \\
\text { secara detail } \\
\text { perihal } \\
\text { klasifikasi yang } \\
\text { baik seperti apa. }\end{array}$ & 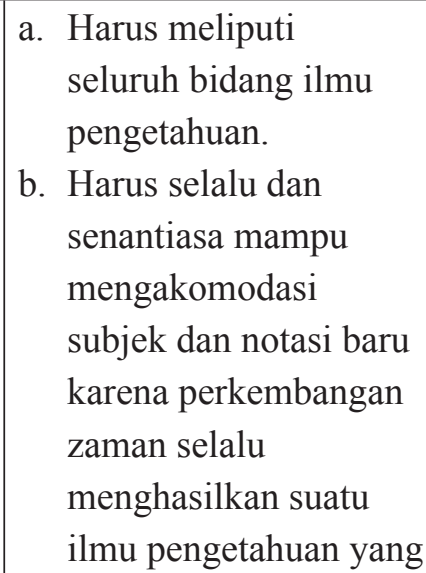 \\
\hline $\begin{array}{c}\text { Mary } \\
\text { Mortimer }\end{array}$ & $\begin{array}{l}\text { a. Harus mudah digunakan serta } \\
\text { dimanfaatkan sesuai dengan tujuan } \\
\text { utama dari sistem klasifikasi. } \\
\text { b. Harus meliputi seluruh ilmu } \\
\text { pengetahuan. } \\
\text { c. Notasinya harus spesifik. } \\
\text { d. Harus memiliki tabel pembagian } \\
\text { geografis dan indeks yang } \\
\text { alfabetis. } \\
\text { e. Harus senantiasa mampu } \\
\text { mengakomodasi notasi baru, } \\
\text { jika ditemukannya suatu ilmu } \\
\text { pengetahuan yang baru. } \\
\text { f. Harus mempunyai suatu badan } \\
\text { pengawas yang ahli pada bidang } \\
\text { sistem klasifikasi. } \\
\text { g. Harus selalu dan senantiasa } \\
\text { dilakukan pengembangan. }\end{array}$ & $\begin{array}{l}\text { a. } \text { Klasifikasi yang } \\
\text { baik adalah } \\
\text { yang mudah } \\
\text { digunakan. } \\
\text { b. Notasi harus } \\
\text { spesifik. } \\
\text { c. Secara gamblang } \\
\text { mengatakan } \\
\text { harus memiliki } \\
\text { tabel pembagian } \\
\text { geografis. } \\
\text { d. Indeks disusun } \\
\text { secara alfabetis. }\end{array}$ & 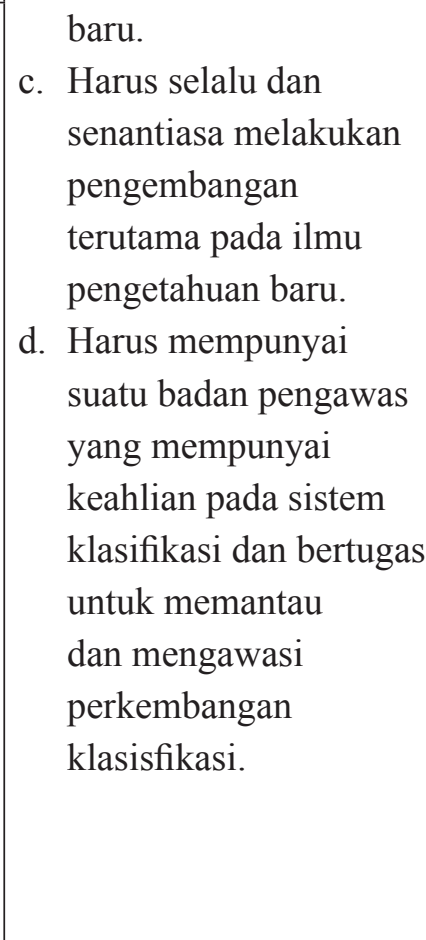 \\
\hline
\end{tabular}

Berdasarkan tabel diatas, maka telah jelas terlihat perbedaan dan persamaan pemikiran kedua tokoh tentang sistem klasifikasi perpustakaan. Dimana Berwick Sayers dan Mary Mortimer mempunyai fokus yang berbeda namun tetap memiliki kesamaan yang signifikan bertujuan untuk mempermudah para penggunanya. Berwick Sayers memberikan pemikiran sistem klasifikasi perpustakaan dengan merujuk pada Library Classification, sedangkan Mary Mortimer merujuk pada Dewey Decimal Classification. Baik LC maupun DDC sampai saat ini masih digunakan di berbagai perpustakaan di seluruh dunia tergantung jenis perpustakaannya, namun untuk saat ini kebanyakan perpustakaan 
menggunakan DDC. Menurut Wayne A. Weigand (1998), di Amerika Serikat sebagai tempat asal dan terbentuknya DDC, sistem klasifikasi DDC telah digunakan oleh 95 persen perpustakaan umum dan perpustakaan sekolah, 25 persen perpustakaan khusus serta 25 persen oleh perpustakaan perguruan tinggi.

\section{KESIMPULAN}

Berdasarkan hasil komparasi dari pemikiran Berwick Sayers dan Mary Mortimer tentang sistem klasifikasi yang baik maka dapat disimpulkan bahwa klasifikasi yang baik adalah klasifikasi yang mudah digunakan serta dimanfaatkan sesuai dengan tujuan utama dari sistem klasifikasi, karena klasifikasi yang baik belum tentu mudah digunakan serta dimanfaatkan terutama dalam proses temu kembali informasi yang dilakukan pemustaka di perpustakaan. Bilamerujukpadakecenderungan dan fokus klasifikasi antara Berwick Sayers dan Mary Mortimer ternyata benar berbeda. Berwick Sayers fokus klasifikasinya merujuk pada Library Classification, sedangkan Mary Mortimer fokus klasifikasinya merujuk pada Dewey Decimal Classification seperti buku miliknya yang jelas membahas Dewey Decimal Classification dan telah menjadi buku pegangan bagi orang-orang yang ingin mendalami ilmu perpustakaan terutama perihal Dewey Decimal Classification. Namun, seperti yang kita ketahui bahwa LCC berbeda dengan DDC. Bila melihat pada realitas perpustakaan di zaman seperti sekarang ini, pemikiran Mary Mortimer lah yang relevan dapat diimplementasikan ke perpustakaan saat ini karena dapat mempermudah dengan mendetail dan mengkomplekskan secara tegas dan signifikan bidang-bidang ilmu pengetahuan. Akan tetapi, saat perpustakaan ingin memilih dan menerapkan sistem klasifikasi mana yang akan digunakan tentunya harus melihat apa saja kebutuhannya, karena pemilihan sistem klasifikasi perpustakaan kesemuanya tergantung pada kebutuhan perpustakaan yang tentunya di sesuaikan dengan kondisi realitas perpustakaannya. Biasanya sistem klasifikasi LCC banyak digunakan pada perpustakaan riset yang ada di Amerika, sedangkan DDC banyak digunakan pada perpustakaan umum, perpustakaan sekolah dan perpustakaan perguruan tinggi.

\section{DAFTAR PUSTAKA}

G.G., Chowdhury. 1999. Introduction to Modern Information Retrieval. London: Association Publishing.

Hamakonda, Towa P. dan J.N.B. Tairas. 1983. Penggantar Klasifikasi Persepuluhan Dewey. Jakarta: Libri.

Indonesia. Undang-Undang Republik Indonesia Nomor 43 Tahun 2007 Tentang Perpustakaan.

Institut Seni Indonesia Yogyakarta. 2018. Perbandingan Klasifikasi DDC Dan Klasifikasi UDC. Dan Klasifikasi UDC. Yogyakarta: Perpustakaan ISI Yogyakarta.

Lasa HS. 2009. Kamus Kepustakawanan Indonesia. Yogyakarta: Pustaka Book Publisher.

Mortimer, Mary. 2007. Learn Dewey Decimal Classification. USA: Total Recall Publications.

Mustaqim, Abdul. 2014. Model Penelitian Tokoh (Dalam Teori dan Aplikasi). Jurnal Studi Ilmu-Ilmu Al-Quran dan Hadis. Vol. 15, No.2.

Olle, James G. 1981. W.C. Berwick Sayers, Librarian adn Teacher. Jurnal Librarianship, 13, (4), October, 1981. https://journals.sagepub.com/doi/ abs/10.1177/096100068101300403.

Diakses 1 Desember 2019.

Rahma, Muswita Widya. 2008. Komparasi 
Bagan Sistem Klasifikasi Dewey Decimal Classification (DDC) Dengan Universal Decimal Classification (UDC). Skripsi. Medan: Universitas Sumatera Utara

Sayers, Berwick. 1918. An Introduction to Library Classification. New York: Grafton \& Coptic House Inc.

Sembiring, Darwis. 2014. Pengolahan Bahan Pustaka: Klasifikasi dan Katalogisasi. Bandung: Yrama Widya.

Sukardi. 2014. Metodologi Penelitian Pendidikan: Kompetensi dan Praktiknya. Jakarta: Bumi Aksara.

Sulistyo-Basuki. 1991. Pengantar Ilmu Perpustakaan. Jakarta: Gramedia Pustaka Utama.

Weigand, Wayne A. 1998. The Origins Of The Dewey Decimal Classification Scheme. Libraries \& Culture. Texas: University of Texas Press.

WorldCat. WorldCat Daring. https://www. worldcat.org/title/learn-deweydecimal-classification-edition-22/ oclc/646784693. Diakses 2 Desember 2019.

Yusuf, Pawit $M$ dan Yaya Suhendar. 2005. Pedoman Penyelenggaraan Perpustakaan Sekolah. Jakarta: Kencana.

Yusuf, Taslimah. 1996. Materi Pokok Manajemen Perpustakaan Umum. Jakarta: Universitas Terbuka. 